\title{
Readiness for and Adoption of Industry 4.0 among Small and Medium Sized Enterprises in the Malaysian Furniture Industry
}

\author{
Lee Yan Yi, ${ }^{\mathrm{a}, *}$ Hazirah Ab Latib, ${ }^{\mathrm{a}, *}$ Jegatheswaran Ratnasingam, ${ }^{\mathrm{a}, *}$ Manohar Mariapan, ${ }^{\mathrm{a}}$ \\ Lim Choon Liat, ${ }^{\mathrm{a}}$ Kamaruzaman Othman, ${ }^{\mathrm{b}}$ Mohd Afthar Amir, ${ }^{\mathrm{b}}$ and Natkuncaran \\ Jegatheswaran $^{\mathrm{c}}$
}

\begin{abstract}
The furniture industry is the fastest growing sub-sector in the Malaysian wood-based industry. Although it has grown tremendously over the years, it is characterized by stagnating value-addition. To improve industrial competitiveness, automation and technology application has emerged as a possible solution. A study was conducted to evaluate the influence of company size towards their readiness and adoptability of automation and Industry 4.0. A questionnaire-based survey involving large-, medium-, small-, and micro-sized furniture manufacturers throughout Malaysia was conducted with 160 respondents. The analysis of the results from the survey showed that there was a significant relationship between company size and their readiness for Industry 4.0. The results showed that smalland medium-sized enterprises (SMEs) are more hesitant in adopting technology due to the high cost required and the lack of skilled workers to cope with the new technology, compared to the large sized companies. The factor analysis revealed that the three main groups of the factor affecting decisions towards adopting industry 4.0 are government policy, difficulty in implementation, and expected benefit. This study suggests that providing incentives for the application of automation and technology will be required when the goal is greater uptake of technology among furniture manufacturers.
\end{abstract}

Keywords: Automation; Furniture; Technology; Industry 4.0; Cost; Skilled labor; Malaysia

Contact information a: Universiti Putra Malaysia, Faculty of Forestry, 43400 UPM, Serdang, Selangor, Malaysia; b: Malaysian Timber Industry Board (MTIB), Level 13-17, Menara PGRM, Jalan Pudu Ulu, 56100 Kuala Lumpur, Malaysia; c: Faculty of Business, University of Wollongong, NSW 2522, Australia;

*Corresponding authors: lyy6247@hotmail.com; hazirahlatib@gmail.com; jegaratnasingam@yahoo.com

\section{INTRODUCTION}

The technology level of the industrial sector in every country is important, as it affects the strength and growth of the manufacturing sector. In fact, Germany's status as an economic powerhouse is dependent on the strength of its manufacturing sector (Sommer 2015). In this context, it is no surprise that the concept of Industry 4.0 was introduced by the German Federal Government as one of the key initiatives of its high-tech strategy in 2011 (Bahrin et al. 2016). The concept of Industry 4.0 is in fact the $4^{\text {th }}$ Industrial Revolution (IR 4.0), where manufacturing and logistics systems in the form of cyber-physical production systems (CPSS), is adopted throughout the manufacturing industry (Strandhagen et al. 2017). 
In realizing the global impact of Industry 4.0, especially when many manufacturing sectors in Malaysia continue to rely on manual labor, the Malaysian government formulated and launched the National IR 4.0 Master Plan in 2018 (MIDA 2018). The main purpose of the master plan was to encourage transformation in the overall manufacturing sector in the country to ensure greater productivity and value-addition through the adoption of relevant technologies (Malay Mail 2019). This is important considering that the manufacturing sector contributes almost $30 \%$ of the country's gross domestic product (GDP), and through relevant technological application, its contribution would become more important, apart from creating more high-skilled employment opportunities (MITI 2018). Further, it was the government's long-term goal that labor-intensive industries, such as wood-based industries, embrace automation and technology application more widely, which would in turn reduce their dependency on manual workers.

\section{The Malaysian Furniture Industry}

Malaysia is ranked within the top 15 largest exporters of furniture in the world (MTIB 2020). Almost 85\% of its annual production is exported to more than 160 countries throughout the world (Ratnasingam et al. 2018). In 2020, the total export of Malaysian furniture was valued at RM (Malaysian Ringgit) 10.3 billion, and the main export destinations included the USA, Japan, United Kingdom, Europe, South Africa, Australia, and the Middle East. However, the Malaysian furniture industry is still considered as a low wage economy due to the lack of innovation and value-addition. In fact, the growth rate of the Malaysian furniture industry from 2003 to 2019 showed a stagnating trend, which shows that the country's furniture sector is losing its global competitiveness. The fact that the Malaysian furniture industry has lost its competitiveness in global markets, despite the on-going $3^{\text {rd }}$ Industrial Master Plan (2006 to 2020), as well as the National Timber Industry Plan (NATIP) that launched in 2009, raises doubts regarding whether the stagnating performance of the Malaysian furniture industry can be reversed (MATRADE 2019; MTIB 2020).

The wood-based industry's performance, including that of the furniture industry in Malaysia, is still considered unsatisfactory compared to international standards, in terms of research and development (R\&D) activities, labor productivity, and value-addition. (Ratnasingam et al. 2017). The Malaysian wood-based industry clearly lags behind their regional counterparts in the South-East Asian region, in terms of labor productivity and value-addition, to an extent that it is beginning to severely impede industrial growth. The owners of furniture factories in Malaysia, usually invest in machines that are specific to certain functions, aiming to reduce labor content, and indirectly reduce manufacturing costs (Ratnasingam et al. 2016). The level of technology applied in the industry is relatively low, because approximately $65 \%$ of the furniture manufacturers still use manual machines, as they are easier to operate and do not need skilled workers (Ngui et al. 2011). The lack of leading furniture companies to lead up the R\&D activities results in an industry that is relatively low in its value-creation (MIDA 2018). Further, the linkages between industry and academia to undertake $R \& D$ activities is also limited.

According to the studies by Ratnasingam et al. (2018, 2019), the main challenges faced by the Malaysian furniture industry are: (1) inconsistent raw materials supply, (2) high dependency on labor-force, (3) slow industrial transformation from the original equipment manufacturing (OEM) to the original design manufacturing (ODM) and original 
brand manufacturing (OBM) strategies, (4) limited value-addition and creativity, and (5) uncertainty in policy directions with the overall timber industry. Inevitably, these challenges affect the overall business sentiments and confidence among stakeholders, especially when it comes to them taking a long-term view of the industry in the country. In this context, it is an opportune time for the labor-intensive furniture manufacturing sector to explore and adopt greater automation and technologies to reverse the flagging fortunes of the industry.

\section{Industry 4.0 and Its Key Technologies}

Industry 4.0 can also be called "smart factory", and there are four design principles that are involved in such a concept (Bartodziej 2017). The first principle is interconnection, which focuses on the sharing of information between interconnected objects and people via the Internet of Things (IoT). The second principle is about information transparency, in which operators make more accurate decisions with the information obtained through the interconnection (Seseni and Mbohwa 2018). Interconnectivity allows the identification of key areas that can be enhanced from innovation and improvement in the manufacturing process (Agostini and Nosella 2019). The third principle is decentralized decision-making, where the cyber physical systems make decisions on their own and perform their task automatically (Jazdi 2014). The fourth principle is technical assistance, in which the system supports humans. This allows the system to support humans by aggregating and visualizing information comprehensively. This can facilitate making informed decisions and solving urgent problems on short notice. The cyber physical systems also conduct a range of tasks that are unpleasant, too exhausting, or unsafe for their human co-workers.

To achieve the objective of the "smart factory", Industry 4.0 involves the application of several key enabling technologies (KET) that are interconnected (Martinelli et al. 2021). Among these technologies are:

(1) Internet of Things - Provides a connection between the devices with selfidentification capabilities, localization, diagnosis status, data acquisition, processing, and implementation via standard communication protocol (Zanella et al. 2014). The concept is based on computer science, communication, information technology, and electronic technology. Internet of Things will continue to have a lasting impact on the manufacturing sector in years to come (Russom 2011).

(2) Big Data Analytics - This technology is about the methods and tools that can process large volumes of data that is from the IoT system for manufacturing, supply chain management, warehouse management, and maintenance (Russom 2011).

(3) Cloud Computing - The key approach in cloud computing is the application of cloud technologies in the manufacturing sector, with widespread access, easy and ondemand IT service-infrastructure, platform, or application support of production processes and supply chain management (Xu 2012). The cloud manufacturing is applicable from virtualization of physical resources necessary for factory equipment to applications, data and processes across platforms and execution-andcollaboration tools, and it is hosted in the cloud (Frank et al. 2019). The cloud computing in manufacturing systems can be implemented in both material and nonmaterial facilities and connects them to support the whole supply chain.

(4) Robotics - Advanced robotics is needed in the advanced automation. The robots should be able to interact with the environment, be self-learning, and be 
automatically guided to use the vision and pattern recognition in production systems to speed up production rate at improved quality levels (Bahrin et al. 2016). The types of industrial robots available include Selective Compliance Articulated Robot Arm (SCARA), Articulated, Cartesian, Dual Arm, and Collaborative Robots (Cobots) (Colim et al. 2019).

(5) Artificial Intelligence (AI) - This technology allows the machine to function appropriately, according to different situations. Artificial intelligence involves computer science-based technologies which, coupled with machine learning, are used to generate intelligent sensors, edge computing, and smart production systems (Badri et al. 2018).

(6) Additive Manufacturing (AM) - A good example of this technology is 3D printing, where it produces an object by depositing layer upon layer of the material in exact geometric shapes. It usually is used in prototyping, manufacturing, maintenance and repair, and modelling functions (Kocsi and Oláh 2017).

\section{Benefits of Industry 4.0}

Industry 4.0 can have a lasting impact not only on humans, but also the equipment, processes, and products (Büchi et al. 2020). Highly automated machine tools and robots, having a high degree of adaptability and flexibility, will replace present equipment. These automated technologies will also lead to reduction in the number of manual workers, although it indirectly creates many high-skilled jobs, especially those required to monitor those automated machine tools and robots in decentralized decision-making (Strandhagen et al. 2017). Industry 4.0 will nevertheless increase the organization's complexity in manufacturing, in which the decision making shall be shifted to decentralized decisionmaking, instead of being done centrally. With specific technologies, such as cloud computing and 3D printing, production processes and product variability will also improve tremendously, leading to higher value-addition.

However, there is still a lack of research regarding the status of automation in the Malaysian furniture industry. In this respect, the objectives of this study were to examine the status of automation in the furniture industry in Malaysia, to analyze the readiness of the Malaysian furniture industry towards the concept of Industry 4.0, and also to evaluate the effect of company size on decision-making related to the adoption of Industry 4.0. This study is particularly of interest as a large proportion of the furniture manufacturing factories in the country are small- and medium-sized enterprises (SMEs), and the findings of the study will assist policymakers in developing relevant strategies to ensure greater adoption of Industry 4.0 technologies among SMEs.

\section{METHODOLOGY}

In this study, both quantitative and qualitative methods were used to collect and compile the research data required. Prior to the start of the study, secondary data related to the objective of the study were collected and compiled from relevant agencies, including the Department of Statistics Malaysia (DOSM), Malaysian Timber Industry Board (MTIB), Malaysian Timber Council (MTC), Malaysian Furniture Council (MFC), and Muar Furniture Association (MFA). This was collected to establish the current status with 
regard to automation and technology application in the wood-based and furniture industries in the country. This was followed by a questionnaire-based survey of selected furniture manufacturers located throughout the country to gather first-hand information related to this study.

\section{Target Respondents}

The assistance of Malaysian Furniture Council (MFC) and Muar Furniture Association (MFA) were obtained to identify suitable respondents for this study, based on their membership database. From a total of 2500 registered furniture manufacturers, of all company-sizes, a total of 330 manufacturers were identified as potential respondents. From this total, only 160 furniture manufacturers consented to participate in the study. The response rate of $48.4 \%$ was considered good, given the fact that many companies were not fully operational during the Covid-19 pandemic that had affected many economic sectors in the country since late 2019. In fact, carrying out the survey was also challenging, as most factories were working at minimal capacity, and therefore, responses to the survey were relatively slow.

\section{Questionnaire-based survey}

To achieve the objectives of the study, the questionnaire was prepared and designed after consultation from industry experts, particularly those in the Malaysian Furniture Council (MFC), Muar Furniture Association (MFA), academics, and previous research by Ratnasingam et al. (2019). In designing the questionnaire, it was important to ensure that the survey covered all types of furniture manufacturers in the country, especially the SMEs. Further, information relevant to answer the objectives of this study were captured through the necessary questions laid out in the survey. This covered aspects such as the extent of automation in the respondent factories, factors that influenced the respondent's decision to adopt Industry 4.0 technologies, and the key enabling technologies of Industry 4.0 that were chosen for adoption by the respondent factories.

The questionnaire was divided into four parts. In the first part, the questions focused on the background of the respondent companies, such as the number of years the company has been in operation, types of furniture produced, number of workers, target market, etc. The second part of the questionnaire constituted three questions, which were aimed at examining the level of automated operations in the respondent companies. The third part of the questionnaire had one question, where the respondent companies were required to identify the factors that affected their decision to adopt Industry 4.0. The factors that were listed as salient factors that influenced their decisions were: no perceived improvement, low application rate, lack of methodical support, absence of government incentives, unclear business benefits, insufficient skills and training, lack of leading companies, unclear government policy, high investment cost, and little awareness of the topic Industry 4.0. These factors were rated based on a five-point Likert's scale of 1 (least influence) to 5 (strongest influence). The fourth part of this questionnaire constituted two questions, which established the key enabling technologies of Industry 4.0 presently used in the respondent companies, and to assess the readiness of the respondent companies towards adopting Industry 4.0. The questionnaire design was verified by the MFC and MFA prior to its implementation. 


\section{Data Collection}

The questionnaire was initially pre-tested among 15 wooden furniture factories in the Klang-Valley, Malaysia, which is a large furniture manufacturing hub in the country. This was to ensure the validity of the questionnaire used. The questionnaire was then modified after receiving the feedback from the respondents during the pre-testing. The modified questionnaire was then dispatched to all the potential respondent companies, and a follow-up reminder was made through telephone calls and email. At the end of the third month, all 160 furniture companies had returned their questionnaire with their responses.

\section{Data Analysis}

The data from the questionnaires were compiled and tabulated using Microsoft Excel (2016) software (Microsoft Corp., Redmond, WA, USA). The statistical software Statistical Package for Social Sciences (SPSS) version 24 (2016) (SPSS LLC, Chicago, IL, USA) was used to analyze the collected data from the questionnaire-based survey. In the study, the factors that affected the respondents' decision in adapting the Industry 4.0 were analyzed. Factor analysis was also used to simplify the many factors that affected the companies' decision to adopt Industry 4.0 into several groups of driving factors, as shown in Table 1. Based on these results, the Spearman's correlation coefficient was used to determine the relationship between the size of the company and the factors that affected their decision to adopt Industry 4.0, as shown in Table 2.

\section{RESULTS AND DISCUSSION}

The results of this study are presented in five parts: (1) the characteristics of the respondent companies, (2) the level of labor intensiveness, (3) factors that affected the company's decision to adopt Industry 4.0, (4) factor analysis of factors that affected the company's decision to adopt Industry 4.0, and (5) technologies of Industry 4.0 presently used by the respondent companies.

\section{Characteristics of Respondent Companies}

Figure 1 shows that most of the respondent companies were operating in Muar and Klang Valley, which were $46.7 \%$ and $30 \%$, respectively, of the total respondent companies. The other areas, such as Butterworth only contributed $11.7 \%$ of the respondent companies. This is to be expected, as Muar has the highest number of furniture factories in Malaysia. From the report by MFA (2019), the vast number of the furniture factories are in Muar and Klang Valley. Further, it was also reported that the Muar furniture factories had contributed approximately MR 6 billion from the total furniture export of MR 11 billion from Malaysia in 2020 (MTIB 2021). This clearly shows that Muar is the most important furniture manufacturing and exporting hub in the country.

The respondent companies in this study were grouped into four categories of large, medium, small, and micro (Fig. 2). It is important to understand the different responses from the companies of different sizes towards technology and Industry 4.0. Almost 80\% of the furniture companies in the country are classified as SMEs, as reported by MFA (2019). According to the study by Johansson et al. (2016), larger companies usually have a consistent production system, and hence they have a larger budget to modify and adapt 
new technologies compared to SMEs. In fact, the study by Ratnasingam et al. (2018) also implied that due to the limited use of technology among SMEs in the furniture industry, productivity compared to the larger companies is lower, which necessitates cost optimization measures to remain profitable. In this context, the objective of this study to examine the relationship between the different sizes of respondent companies and the factors that hindered their decision to adopt Industry 4.0 is relevant.

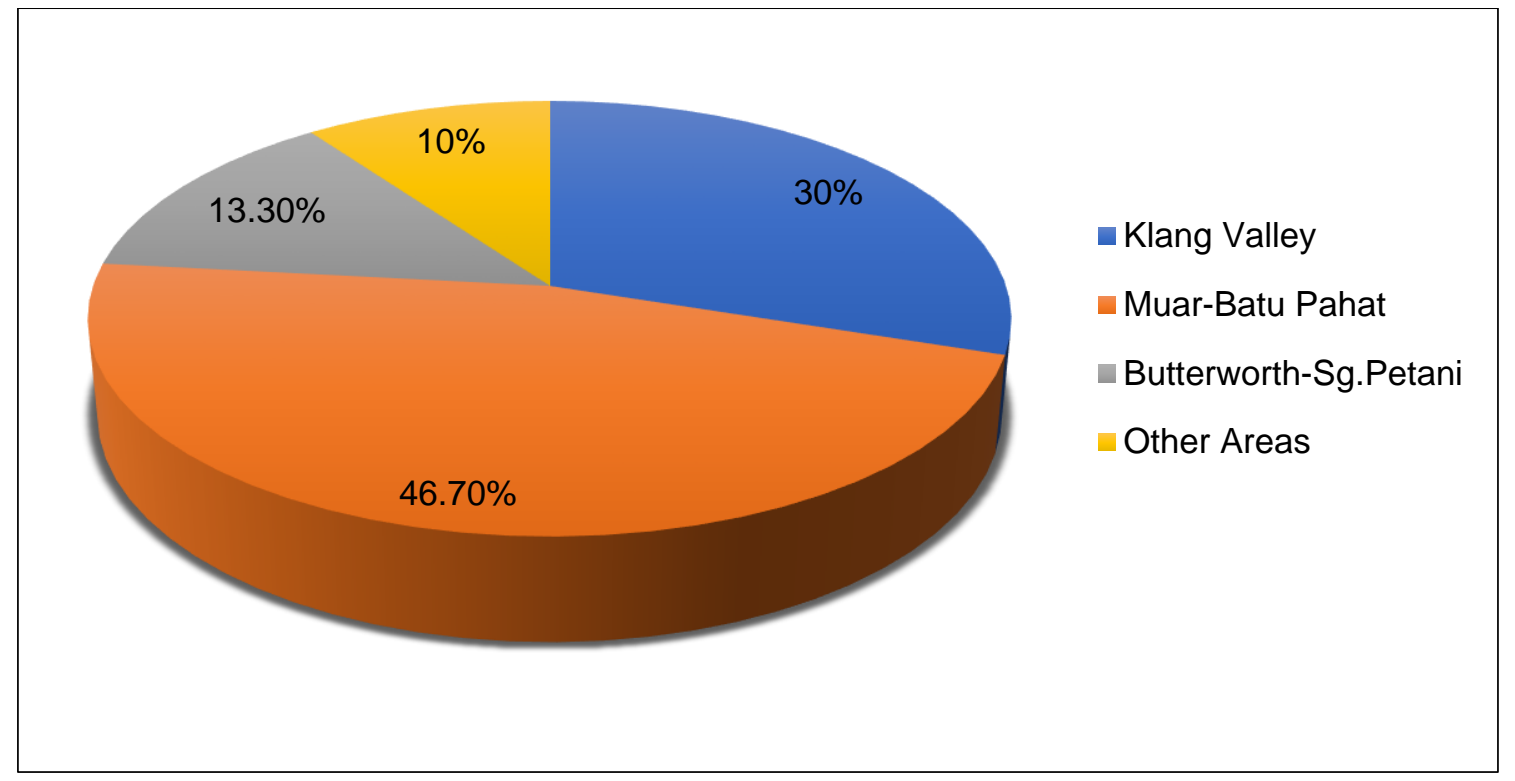

Fig. 1. Location of respondent's company

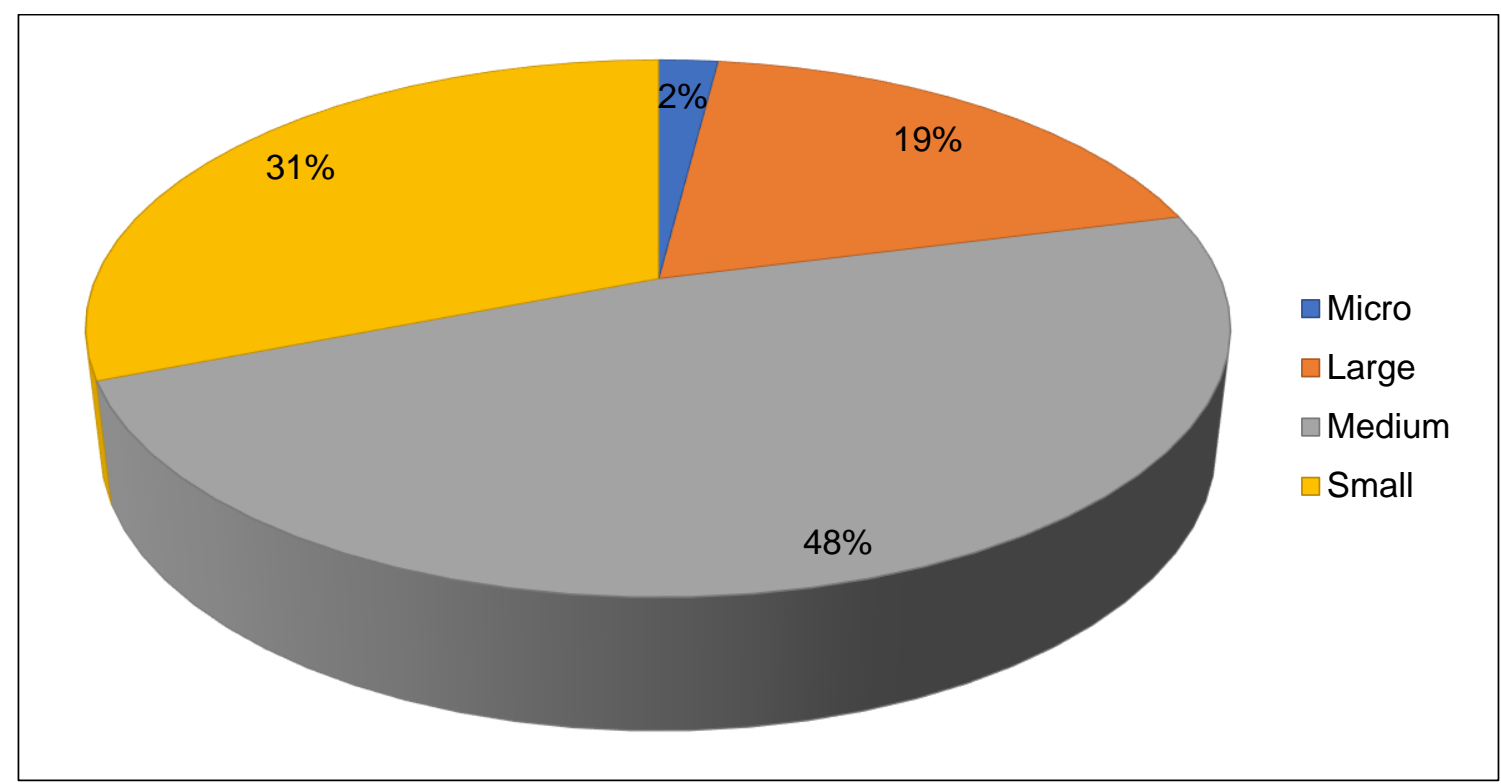

Fig. 2. Size of the respondent's company

Figure 3 shows that most of the respondent companies had $100 \%$ of their products exported to other countries. This observation is in line with the study by Ratnasingam et al. (2020), which reported that $85 \%$ of Malaysia's furniture production is exported, and the 
country is one of the top 10 furniture exporters in the world. The major export destinations for Malaysian-made furniture include the United States (US), Japan, Singapore, Australia, Europe, United Kingdom (UK), South Africa, and the Middle East.

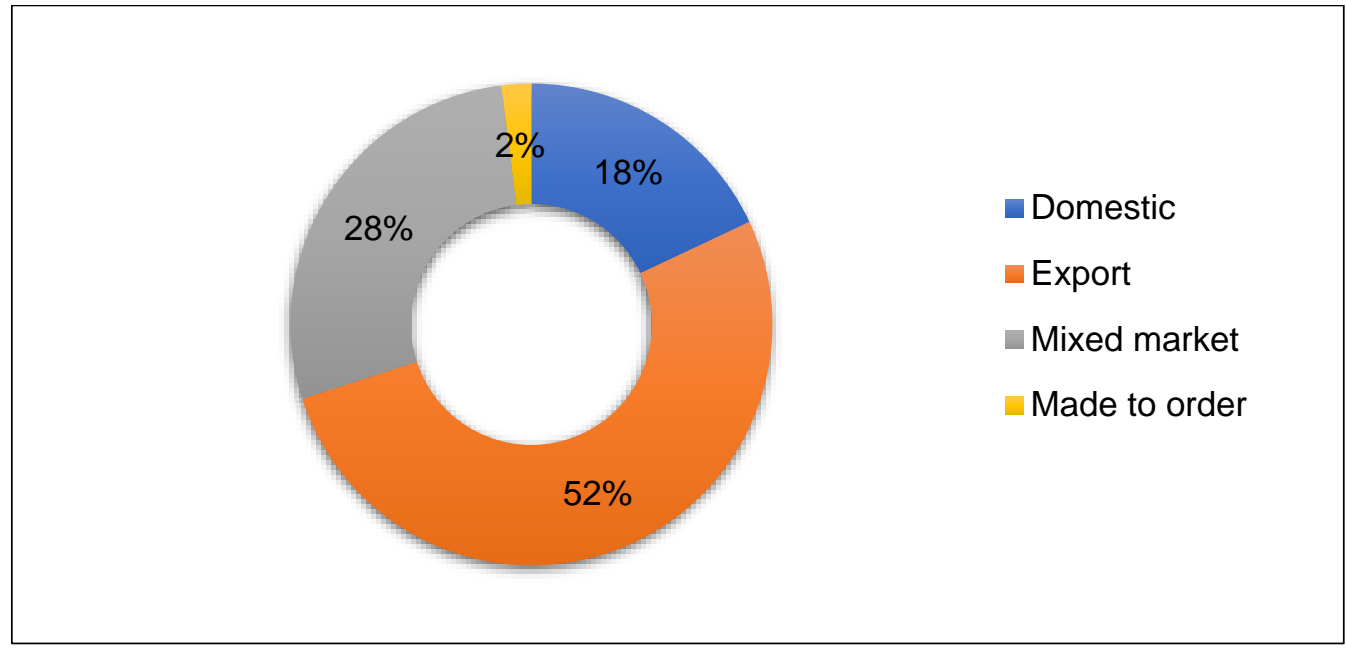

Fig. 3. Nature of sales

\section{Level of Automated Operations in Respondent Companies}

As shown in Fig. 4, almost $50 \%$ of the respondent companies had only $20 \%$ or less of their operations with some degree of automation applied in their respective factories. This showed that the Malaysian furniture industry is still heavily dependent on manual labor, and the application of automation and technology is limited.

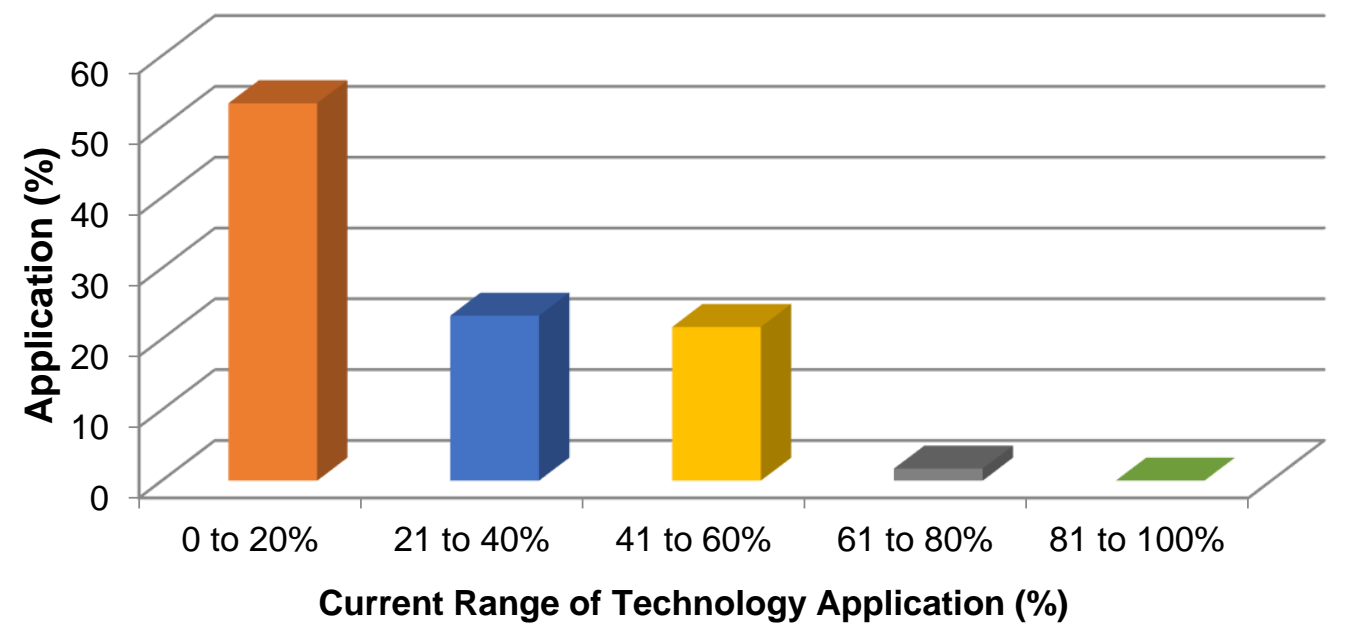

Fig. 4. Extent of automated operations in respondent companies

This result is in line with the study by Ratnasingam et al. (2018), which stated that the level of automation of the furniture industry in Malaysia was between Industry 2.0 and Industry 3.0, which is lagging compared not only to other manufacturing sectors in the country, but also to neighboring countries, such as Thailand, in the wood products industry. This is attributed to the fact that most of the companies in the furniture industry are SMEs, 
with limited financial capabilities, and therefore, the impetus to invest in technology is restricted (Zawadzki and Żywicki 2016).

Further, the results of the survey also showed that $92 \%$ of the respondent companies had the least number of workers in their rough mill section. In contrast, $72 \%$ of the respondent companies had the highest number of workers in the sanding section, as shown in Fig. 5. This was to be expected, as sanding operation has been reported to be a laborintensive operation in furniture manufacturing (Ratnasingam et al. 2016). Further, the report by Zawadzki and Żywicki (2016) also argued that the main reason for the laborintensive nature of the sanding operation in furniture manufacturing is the need to accommodate the machining of edges, curves, and different profiles of the furniture.

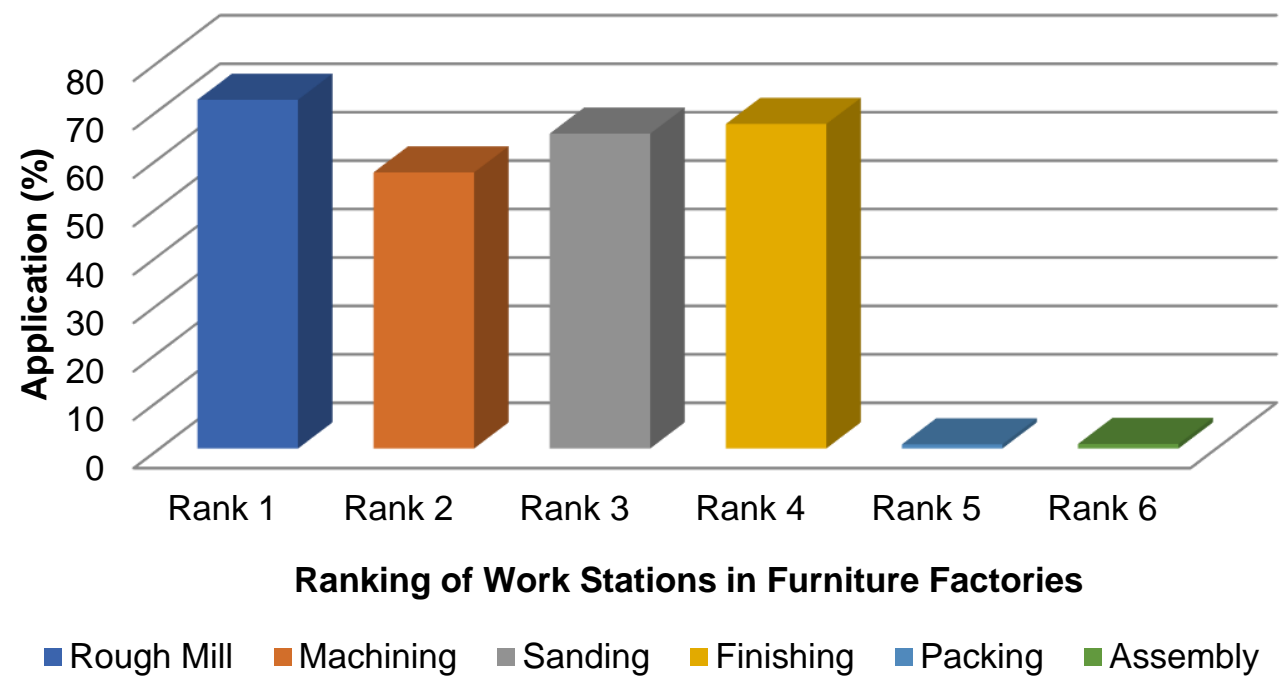

Fig. 5. Degree of labor intensiveness by major manufacturing sections

Considering this observation, it is worthy to note that panel-based furniture manufacturing has relatively lower proportion of sanding and other manual operations compared to other types of furniture manufacturing. In the report by Ratnasingam et al. (2019), it was suggested that the wood-based panel furniture manufacturing also shows a higher degree of adoption of automation and technology among all other type of furniture manufacturing industries. In fact, the wood-based panel furniture industry is also relatively open to the adoption to Industry 4.0 technologies and have shown greater readiness to its adoption.

\section{Factors Hindering the Company's Decision to Adopt Industry 4.0}

Figure 6 shows the factors that hindered respondent companies from adopting Industry 4.0. It is apparent that the limited or lack of interest among the early pioneers to explore and adopt key technologies of Industry 4.0, was an important reason that hindered companies from exploring Industry 4.0 technologies. Early pioneers serve as a role model, which is important to furniture manufacturers who often share their experiences among the peers in their industry (Ratnasingam et al. 2019). Without early pioneers, who champion and provide encouragement to their peers in the industry, uptake of new technologies will suffer in the industry. 


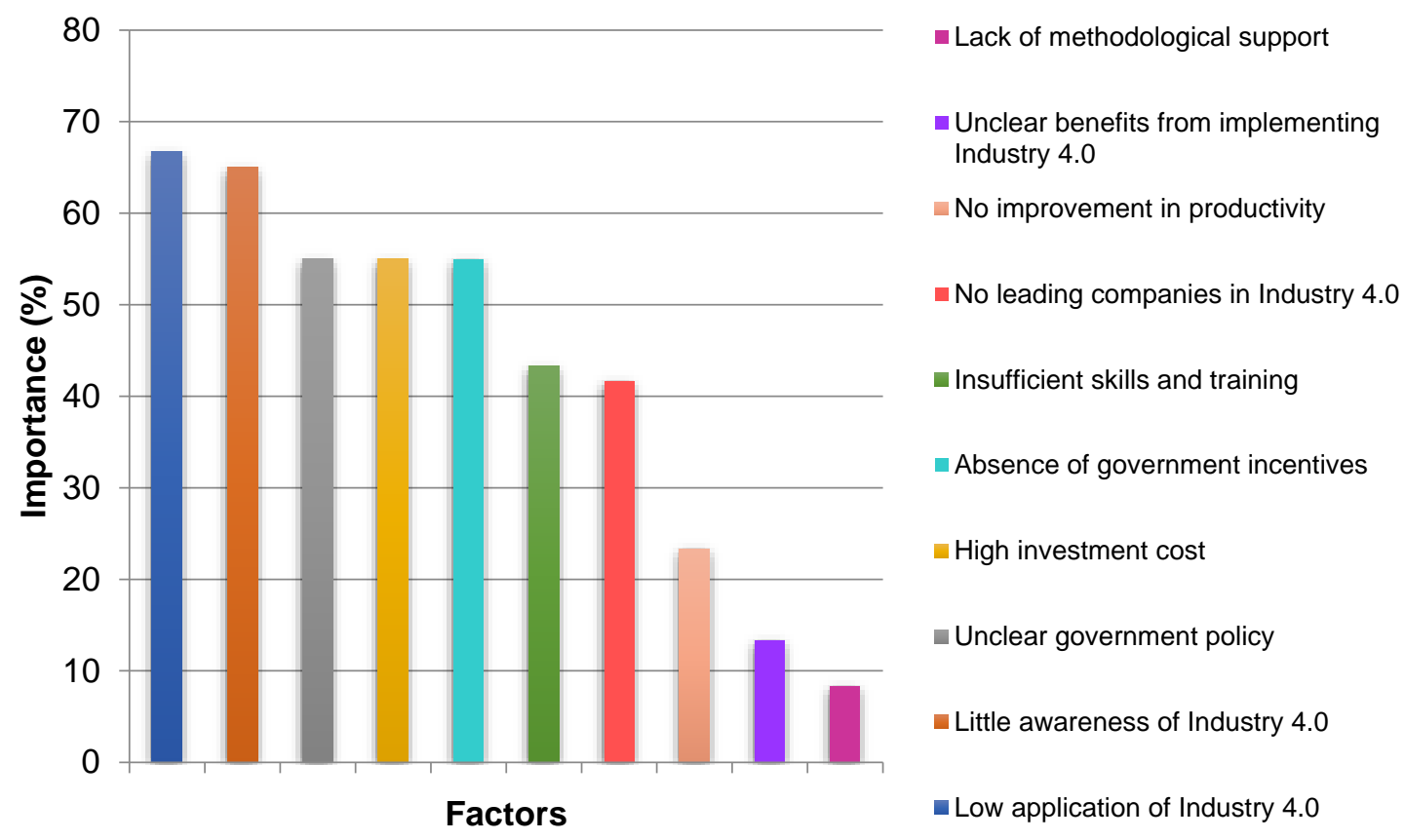

Fig. 6. Factors that hindered respondents from adopting Industry 4.0

Further, the lack of awareness of the concept of Industry 4.0 is another important factor that appears to hinder wider adoption of this technology among the respondent companies. The result is in line with the study by Schröder (2016), who stated that the application of new technology in the manufacturing sector could be increased, through increased awareness among the manufacturers. Other factors that deterred the respondent companies from adopting Industry 4.0 technologies include the high initial investment cost and the low rate of return from the investment (Ratnasingam et al. 2019). Additionally, $50 \%$ of the respondents also claimed that the unclear government policy did not encourage them to consider these technologies. The insufficient skills and training provided to workers in Malaysia, especially those related to technologies of Industry 4.0, was also a major concern among respondents (Ratnasingam et al. 2020). This point limited the motivation of respondent companies to adopt Industry 4.0, which required a skilled and knowledge-based workforce. Masood and Egger (2019) reported that SMEs were challenged when adopting an additive manufacturing (AM) system, due to the lack of skill and knowledge among their workers. It must also be highlighted that the use of foreign contract workers also aggravates the problem, as training them is deemed futile by many manufacturers as they are often treated as temporary workers (Ratnasingam et al. 2018).

\section{Factors Affecting Company's Decision to Adopt Industry 4.0}

The factor analysis was carried out to categorize the set of ten factors that affected the respondent companies to adopt Industry 4.0 into smaller groups, and the results gave three distinct sub-groups, which are ranked by their importance. The three factors were: (1) government policy, (2) expected benefits, and (3) difficulty in implementation, as shown in the Table 1. The variance for Factor 1, Factor 2, and Factor 3 accounted for $38.0 \%, 18.5 \%$, and $10.7 \%$ respectively, of the total variance observed among the factors. The results show that the decision for respondent companies to invest in Industry 4.0 was 
strongly affected by government policy, unclear expected benefits from the adoption of Industry 4.0, and difficulty in implementing Industry 4.0. The study by Ratnasingam et al. (2018) also pointed out that government played an important role in motivating the manufacturing sector in the adoption of Industry 4.0. Even with the launch of National Policy on Industry 4.0 by MITI (2018), the specific incentives for the furniture and woodbased industry were unclear, and hence the interest among respondent companies was limited (MIDA 2018). A clearer picture of the benefits to be derived from the application of Industry 4.0 technologies, would boost the motivation of companies to adopt Industry 4.0 (Masood and Sonntag 2020).

Table 1. Factors Affecting Company's Decision to Adopt Industry 4.0

\begin{tabular}{|c|c|c|c|}
\hline No. & Factors & Factor Loading & Attributes \\
\hline \multirow[t]{6}{*}{1} & \multirow{6}{*}{$\begin{array}{l}\text { Government } \\
\text { policy }\end{array}$} & 0.81 & Little awareness of the topic Industry 4.0 \\
\hline & & 0.86 & High investment cost \\
\hline & & 0.73 & Unclear government policy \\
\hline & & 0.89 & Lack of leading companies in industry 4.0 \\
\hline & & 0.77 & Insufficient skills and trainings \\
\hline & & 0.71 & Absence of government incentives \\
\hline \multirow[t]{2}{*}{2} & \multirow[t]{2}{*}{ Expected benefits } & 0.59 & $\begin{array}{l}\text { Unclear business benefits originating from } \\
\text { implementation of Industry } 4.0\end{array}$ \\
\hline & & 0.54 & No perceived improvement in productivity \\
\hline \multirow[t]{2}{*}{3} & \multirow{2}{*}{$\begin{array}{l}\text { Difficulty in } \\
\text { implementation }\end{array}$} & 0.41 & Lack of methodological support \\
\hline & & 0.46 & $\begin{array}{c}\text { Low application rate of supporting } \\
\text { technologies }\end{array}$ \\
\hline
\end{tabular}

Note: Factors rated using a 5-point Likert scale of 1 to 5

The relationship between the size of the respondent company and their decision to adopt industry 4.0 was then examined using Spearman correlation analysis. Table 2 shows that most of the variables had Spearman's correlation coefficient values between 0.3 and 0.8, which suggested an intermediate positive relationship between the size of the respondent companies and the variables chosen as deterrents against adopting Industry 4.0 technologies. This meant that the size of the company had a significant influence on the decision to adopt Industry 4.0 technologies. Generally, larger companies tend to have a larger budget to invest in technologies compared to SMEs, and therefore they are more readily open to the adoption of technologies of Industry 4.0. On the other hand, the SMEs are constrained by the limited financial strength, which not only limits their ability to invest in technology, also impairs their ability to have the necessary inputs, in terms of trained human capital and support systems, which are necessary to maintain and operate these technologies productively. A similar finding was also reported by Agostini and Nosella (2019), who stated that the size of the company had a strong influence on the decision of the company to adopt Industry 4.0. This is particularly of interest, as most of the companies in the Malaysian furniture industry are SMEs, and therefore they may be constrained by the ability to invest in automation and technology (Ratnasingam et al. 2019). Thus, to boost the adoption of such technologies among SMEs in the furniture industry, incentivizing such adoption may be considered. 
Table 2. Correlation of Reasons That Affected the Company's Decision to Adopt Industry 4.0

\begin{tabular}{|c|c|}
\hline Variable & Correlation Coefficient \\
\hline Little awareness of the topic Industry 4.0 & $0.813^{*}$ \\
\hline High investment cost & $0.698^{*}$ \\
\hline Absence of government regulation & $0.574^{*}$ \\
\hline Lack of leading companies in Industry 4.0 & $0.621^{*}$ \\
\hline Insufficient skills and training & $0.618^{*}$ \\
\hline $\begin{array}{c}\text { Unclear business benefits originating from } \\
\text { implementation of Industry 4.0 }\end{array}$ & 0.000 \\
\hline Absence of government incentives & $0.739^{*}$ \\
\hline Lack of methodological support & -0.074 \\
\hline Low application rate of Industry 4.0 & $0.346^{*}$ \\
\hline No perceived improvement in productivity & -0.241 \\
\hline
\end{tabular}

In fact, the biggest obstacle for SMEs to adopt technology was the cost of the investment involved (Türkeș et al. 2019). There appears to be the perception that the cost needed to invest in Industry 4.0 exceeded what most SMEs could afford, even though the technology could bring significant profit in the long term. Research by Marjanovic et al. (2017) also argued that the SMEs faced other challenges, such as poor financial strength, lack of technical skills in workers, and the unaffordable maintenance cost to support automation technologies, which explained their poor uptake of Industry 4.0 technologies.

The Malaysian furniture industry is also highly labor dependent, and as a result is also reluctant to explore new technologies (Noor et al. 2011; Palel et al. 2016). Around $80 \%$ of the workers in Malaysia are contract foreign workers (Athukorala and Devadason 2012), who lack the skills to apply technologies effectively. Therefore, without a permanent workforce, companies are usually conservative in their approach towards technology and may try to keep investment to the lowest possible level (Zhihui 2016; Yin et al. 2018). Furthermore, a permanent workforce is better to provide training for, instead of the contract foreign workforce, as the training costs involved are also usually high (Ajis et al. 2014).

\section{Technologies of Industry 4.0 Presently Used by Respondent Companies}

Although the overall adoption of Industry 4.0 among the SMEs in the furniture industry in Malaysia is low, Fig. 7 shows that three technologies of Industry 4.0 appear to have found more acceptance among the respondent companies. These technologies are low-cost automation (LCA) (73\%), materials requirement planning (MRP) (63\%), and computer-aided design (CAD) (50\%). The CAD system, also known as auto-CAD, is commonly used in furniture design activities (Dan 2017), and it is usually paired with computer-aided manufacturing (CAM) to control automated machines (Wang and $\mathrm{Wu}$ 2016). The MRP was popular among the furniture manufacturers to assist in planning, scheduling, and the managing of inventory and work-in-progress during the manufacturing processes (Dan 2017). A study by Loucopoulos et al. (2020) also suggested that MRP boosted optimization of inventory management, manufacturing efficiency, labor productivity, and overall customer satisfaction. According to the study by Müller-Polyzou et al. (2020), LCA was popular among furniture manufacturers due to its suggested low investment cost, which means technology that has a short return on investment period. 
Low-cost automation is the combination of some equipment and tools methods with some degree of automation, which allows higher through-put rate and improved productivity to be achieved, without major investment commitments (Colim et al. 2019). However, it must be noted that these three technologies have been traditionally promoted as productivity enhancement tools to the furniture industry long before the concept of Industry 4.0 became apparent (Stentoft et al. 2020).

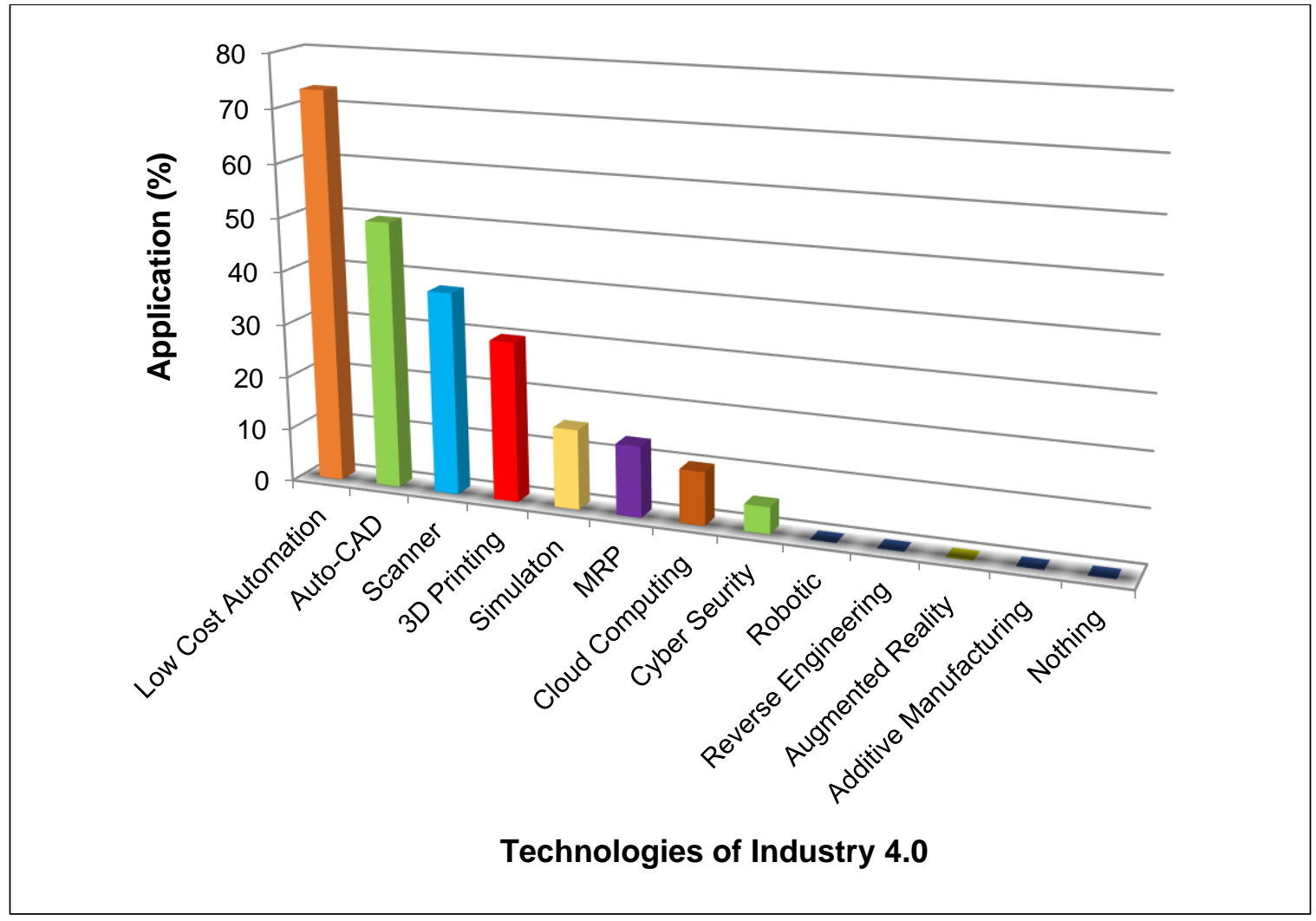

Fig. 7. Technologies of Industry 4.0 presently used in respondent companies

Unlike the key enabling technologies of Industry 4.0, this study shows that technologies such as Auto-CAD, MRP, and low-cost automation, which are traditionally technologies of the Third Industrial Revolution, indicates that the furniture manufacturing industry remains an industry that is starved of investment and technology (Ratnasingam et al. 2019). Such technology application is indeed common in the cost-sensitive furniture manufacturing industry, where the expected return on investment (ROI) must often be short for such technologies. Inevitably, it explains the reluctance of furniture manufacturers, especially the SMEs, who are financially constrained and as a result often delay their investment in technology application, unless it is through government support. The results also imply that rather than expecting an industry-wide adoption of technologies of Industry 4.0 , it is important that a readiness assessment (RA) of the manufacturers be carried out initially, before the most appropriate technology is introduced to the manufacturing facility. Afterall, there have been many initiatives, where the machinery and technology have been provided to manufacturers through government assistance, but the outcomes have been dismal due to a complete mismatch of the needs and readiness (Ratnasingam et al. 2020). 
Other than the three technologies mentioned above, the other technologies of Industry 4.0 have found limited application among the respondent companies. Technologies such as 3D printing, additive manufacturing, simulation, and scanning are very much in the infancy in its application in the Malaysian furniture industry, although furniture manufacturers with in-house design and product development activities are increasing. Such technologies are being employed to shorten their product development and prototyping cycle. On the other hand, companies are moving towards digitization and digitalization of the operations, especially marketing activities, which tend to be more receptive to technologies such as simulation, cloud computing, as well as augmented reality. It has been noted that the respondents of this study also indicated product development and marketing activities as the two main areas, which are likely to adopt technologies in Industry 4.0 in the very near future. This is to be expected as the global Covid-19 pandemic has certainly accelerated the digital marketing activities of many furniture manufacturers since early 2020 (Ratnasingam et al. 2020). Robotics and reverse engineering were also indicated as the emerging technologies by manufacturers involved in the panel-based furniture industry, which is often produced in a modular system. Finally, there were respondents who have not adopted any technologies over the years, and continue to remain a manual operation, suggesting that there are furniture enterprises in the country that still operate as a craft-based manual operation.

Nevertheless, it is apparent that readiness for Industry 4.0 technologies in the furniture industry in Malaysia is relatively low, as the present state of automated technologies application is relatively low. This finding runs parallel to the reports by Tan (2018) and Ratnasingam et al. (2020), who noted the relatively low Industry 4.0 readiness level among furniture and wood products manufacturers in the country.

\section{Implications of the Findings}

The results of this study reveal some important points that must be taken into consideration if the government's intention to increase the level of automation and technology application in the furniture industry is to be accomplished. The findings clearly show that furniture manufacturing in Malaysia, which is predominated by SMEs, is constrained by their ability to invest in automation and technology, apart from the lack of skilled workers to effectively manage these technologies. In this context, policy framework that incentivizes the adoption of technology, which will undoubtedly increase industrial productivity and reduce the industry's dependence on foreign contract workers, must be made clear among the furniture manufacturers (Ratnasingam et al. 2018). In this context, upskilling of the present workforce through intensive training programs may be a pathway worth considering, as replacing the workforce immediately may not be advisable and often takes time (Sommer 2015; Agostini and Nosella 2019). Further, it may be naive on the side of policymakers to adopt a one-size-fit all approach, as some furniture products manufacturing may still require labor-content and cannot be fully automated. Panel-based, metal, and plastic furniture are the likely potential sub-sectors within the furniture industry that have a high adoption level for technology, compared to wooden furniture manufacturing. In fact, the wood-based panel furniture industry has also been proactive in adopting automation and technologies to boost their productivity over the last few years (Ratnasingam et al. 2019). In this respect, the adoption of automation and technologies must be gradual in the furniture industry and must be carried out incrementally depending 
on the type of furniture manufactured. Previous research has also suggested that companies that are more systematic and have adopted a lean manufacturing (LM) system, are often suitable candidates for further embracing automated technologies (Kumar et al. 2020). Because the uptake of the LM system is more prevalent among larger furniture manufacturers compared to the SMEs in the industry (MTIB 2020), this also clearly indicates that a similar trend is to be expected when it comes to technologies of Industry 4.0. Perhaps the readiness assessment of IR 4.0 should be made throughout the furniture industry, without considering the size of the companies involved. This may provide a better picture to policymakers on the necessary action plan that must be implemented to ensure greater acceptance of the policy among players in the furniture and wood-based sectors. This study shows that SMEs who make the largest proportion of furniture manufacturers in the country will have to be supported with financial assistance, apart from the provision of skilled workers, training programs, digitalization incentive, and other supporting systems, if greater adoption of technology is to be realized within the furniture industry. It must be emphasized that performance of the SMEs can have a far-reaching impact on the overall performance of the Malaysian furniture industry, as they contribute almost $74 \%$ of the annual production output, apart from accounting for nearly $69 \%$ of the workforce in the industry. In fact, the strength of the SMEs in the Malaysian furniture industry has been severely tested during the Covid-19 pandemic, as their production was halted for several months during the movement control order (MCO) period introduced by the government to curb the spread of the virus. Inevitably, the underlying resilience of the SMEs has been dented, as many of them faced financial difficulty, resulting in workers layoff as well as production losses. Against this background, this may present an opportune time for the further application of automation and technology, but it must be supported and fit their requirements.

In fact, the findings of this study are parallel to the Census of the Malaysian Timber Industry conducted in 2019 (MTIB 2020). It was shown conclusively that the growth of the Malaysian furniture sector is fueled by incremental capital inputs, especially raw materials, and workforce, rather than actual productivity gains. The predominance of the SMEs in this sector also implies that uptake of automation and technology will be slow, and without the necessary incentives and government support, such adoption may not be fully realized. The findings of the census also suggested that many of the policy instruments pertaining to the Malaysian furniture industry failed to realize their goals, due to a mismatch between intention and industrial practice. Such a mismatch does not benefit the industry, which is under tremendous pressure to remain competitive due to the presence of other low-cost furniture producers in the Asian region.

In this context, it is important that the necessary tweaking of the strategies and action plans are undertaken to ensure that the furniture industry draws the desired benefits from the National Policy on IR4.0 that was launched by the government in 2018 (Moeuf et al. 2018; Ratnasingam et al. 2020).

\section{CONCLUSIONS}

1. The status of automation application in Malaysia furniture industry is relatively low, and the industry remains labor-intensive. The result of this study revealed SMEs were less automated compared to larger companies.

Yi et al. (2021). "Company size \& Industry 4.0," BioResources 16(4), 8289-8308. 
2. Correlation coefficient analysis revealed that the factors that influenced the company's decision to invest in Industry 4.0 are the level of awareness of Industry 4.0, high investment cost, lack of leading companies applying Industry 4.0, insufficient skills and training for such technologies, and the limited government incentives and financial support.

3. Further, the study clearly shows that company size plays a role in adopting technologies, and generally larger sized companies are more receptive to adopting technologies of Industry 4.0.

4. Factor analysis revealed that the application of automation is driven primarily by government policy, expected benefits, and difficulty in implementation, in the order of declining importance.

5. Auto-CAD, material resource planning (MRP), and low-cost automation were the three key technologies of Industry 4.0 currently employed by the respondents.

\section{ACKNOWLEDGEMENTS}

The authors are grateful to the Malaysian Furniture Council (MFC) and Muar Furniture Association (MFA) for assistance in conducting the survey. The financial assistance from University Putra Malaysia through the Putra-Grant No. 9469900 to undertake this study is also acknowledged.

\section{REFERENCES CITED}

Agostini, L., and Nosella, A. (2019). "The adoption of Industry 4.0 technologies in SMEs: Results of an international study," Management Decision 58(4), 625-643. DOI: 10.1108/MD-09-2018-0973

Ajis, M. N., Keling, M. F., Othman, Z., and Shuib, S. (2014). "The dilemma of managing foreign workers in Malaysia: Opportunities and challenges," Global Journal of Human Social-Science: Political Science 14(4), 43-53.

Athukorala, P. C., and Devadason, E. S. (2012). "The impact of foreign labor on host country wages: The experience of a southern host, Malaysia," World Development 40(8), 1497-1510. DOI: 10.1016/j.worlddev.2012.04.025

Badri, A., Boudreau-Trudel, B., and Souissi, A. S. (2018). "Occupational health and safety in the industry 4.0 era: A cause for major concern?," Safety Science 109, 403411. DOI: $10.1016 /$ j.ssci.2018.06.012

Bahrin, M. A. K., Othman, M. F., Azli, N. H. N., and Talib, M. F. (2016). "Industry 4.0: A review on industrial automation and robotic," Jurnal Teknologi 78(6-13), 137-143. DOI: $10.11113 /$ jt.v78.9285

Bartodziej, C. J. (2017). "The concept industry 4.0," in: The Concept Industry 4.0, Springer Gabler, Wiesbaden, Germany, pp. 27-50. DOI: 10.1007/978-3-658-16502-4

Büchi, G., Cugno, M., and Castagnoli, R. (2020). "Smart factory performance and Industry 4.0," Technological Forecasting and Social Change 150, article ID 119790. DOI: 10.1016/j.techfore.2019.119790 
Colim, A., Costa, S., Cardoso, A., Arezes, P., and Silva, C. (2019). "Robots and human interaction in a furniture manufacturing industry-risk assessment," in: Proceedings of the International Conference on Applied Human Factors and Ergonomics, Springer, Cham, Switzerland, pp. 81-90. DOI: 10.1007/978-3-030-20497-6_8

Dan, Z. (2017). "Furniture design method based on CAD technology," in: 2017 International Conference on Smart Grid and Electrical Automation (ICSGEA), IEEE, New York, NY, USA, pp. 73-76. DOI: 10.1109/ICSGEA.2017.121

Frank, A. G., Dalenogare, L. S., and Ayala, N. F. (2019). "Industry 4.0 technologies: Implementation patterns in manufacturing companies," International Journal of Production Economics 210, 15-26. DOI: 10.1016/j.ijpe.2019.01.004

Jazdi, N. (2014). "Cyber physical systems in the context of Industry 4.0," in: 2014 IEEE International Conference on Automation, Quality and Testing, Robotics, AQTR, IEEE, New York, NY, USA, pp. 1-4. DOI: 10.1109/AQTR.2014.6857843

Johansson, J., Blomqvist, L., Nilson, H., and Landscheidt, S. (2016). "Influencing factors to enable automation of wood furniture production," in: Proceedings of the $12^{\text {th }}$ Annual Meeting of the Northern European Network for Wood Science and Engineering WSE, B. Andersons, and A. Kokorevics (eds.), Latvian State Institute of Wood Chemistry, Riga, Latvia, pp. 208-213.

Kocsi, B., and Oláh, J. (2017). "Potential connections of unique manufacturing and industry 4.0,” LogForum 13(4), 389-400. DOI: 10.17270/J.LOG.2017.4.1

Kumar, R., Singh, R. K., and Dwivedi, Y. K. (2020). "Application of industry 4.0 technologies in SMEs for ethical and sustainable operations: Analysis of challenges," Journal of Cleaner Production 275, article ID 124063. DOI: 10.1016/j.jclepro.2020.124063

Loucopoulos, P., Kavakli, E., and Chechina, N. (2020). "Requirements engineering for cyber physical production systems," in: Advanced Information Systems Engineering. CAiSE 2019. Lecture Notes in Computer Science, P. Giorgini and B. Weber (eds.), Springer, Cham, Switzerland, pp. 276-291. DOI: 10.1007/978-3-03021290-2_18

Malay Mail (2019). "Malaysia exports RM22.5b wood-based products in 2019," (https://www.malaymail.com/news/money/2020/09/07/malaysia-exports-rm22.5bwood-based-products-in-2019/1900927), Accessed 1 Oct 2020.

Malaysian Timber Industry Board (MTIB) (2020). Annual Report of the Malaysian Wood Industry 2019, Malaysian Timber Industry Board, Kuala Lumpur, Malaysia.

Malaysian Timber Industry Board (MTIB) (2020). Census of the Malaysian Timber Industry. Malaysian Timber Industry Board, Kuala Lumpur, Malaysia.

Malaysian Timber Industry Board (MTIB) (2021). Annual Report of the Malaysian Wood Industry 2020, Malaysian Timber Industry Board, Kuala Lumpur, Malaysia.

Marjanovic, U., Lalic, B., Delić, M., and Tasic, N. (2017). "Industry 4.0: Evidence from transitional economy," in: Ninth $\left(9^{\text {th }}\right)$ Annual International Conference on Global Business, Engineering, Energy, Agriculture and Health 2017, Chicago, IL, USA, pp. 92-102.

Martinelli, A., Mina, A., and Moggi, M. (2021). "The enabling technologies of industry 4.0: Examining the seeds of the fourth industrial revolution," Industrial and Corporate Change 30(1), 161-188. DOI: 10.1093/icc/dtaa060 
Masood, T., and Egger, J. (2019). "Augmented reality in support of Industry 4.0 Implementation challenges and success factors," Robotics and Computer-Integrated Manufacturing 58, 181-195. DOI: 10.1016/j.rcim.2019.02.003

Masood, T., and Sonntag, P. (2020). "Industry 4.0: Adoption challenges and benefits for SMEs," Computers in Industry 121, article ID 103261. DOI: 10.1016/j.compind.2020.103261

MATRADE (2019). "Malaysian furniture export performance shows growth," (http://www.matrade.gov.my/en/about-matrade/media/press-releases/4674-malaysianfurniture-export-performance-shows-growth), Accessed 20 June 2020.

MFA (2019). Status of Furniture Industry in the Muar Cluster in Johor, Malaysia, Internal Report, MFA Press, Johor, Malaysia.

Malaysian Investment Development Authority (MIDA) (2018). Malaysian National Policy for Industry 4.0 Malaysia Industrial Development Authority, Ministry of International Trade and Industry, Kuala Lumpur, Malaysia.

Ministry of International Trade and Industry (MITI) (2018). Status of Digital Technology Application in the Manufacturing Sector in Malaysia, MITI Press, Kuala Lumpur, Malaysia.

Moeuf, A., Pellerin, R., Lamouri, S., Tamayo-Giraldo, S., and Barbaray, R. (2018). "The industrial management of SMEs in the era of Industry 4.0.," International Journal of Production Research 56(3), 1118-1136. DOI: 10.1080/00207543.2017.1372647

Müller-Polyzou, R., Meier, N., and Georgiadis, A. (2020). "Case study analysis of laserassisted low-cost automation assembly," IFAC-PapersOnLine 53(2), 10403-10410. DOI: 10.1016/j.ifacol.2020.12.2780

Ngui, K. S., Agrawal, A., and Voon, J. P. (2011). "Challenges impeding competitiveness of the wooden furniture manufacturing industry: The case of furniture industry in Sarawak, Malaysia," Australian Journal of Basic and Applied Sciences 5(9), 1135 1145. DOI: $10.2139 /$ ssrn.1951631

Noor, Z. M., Isa, N., Said, R., and Abd Jalil, S. (2011). "The impact of foreign workers on labour productivity in Malaysian manufacturing sector," International Journal of Economics and Management 5(1), 169-178.

Palel, N. S. M., Ismail, R., and Awang, A. H. (2016). "The impacts of foreign labour entry on the labour productivity in the Malaysian manufacturing sector," Journal of Economic Cooperation and Development 37(3), 29-56.

Ratnasingam, J., Ab Latib, H., Yi, L., Liat, L., and Khoo, A. (2019). "Extent of automation and the readiness for industry 4.0 among Malaysian furniture manufacturers," BioResources 14(3), 7095-7110. DOI: 10.15376/biores.14.3.70957110

Ratnasingam, J., Ark, C. K., Mohamed, S., Liat, L. C., Ramasamy, G., and Senin, A. L. (2017). "An analysis of labor and capital productivity in the Malaysian timber sector," BioResources 12(1), 1430-1446. DOI: 10.15376/biores.12.1.1430-1446

Ratnasingam, J., Chin, K. A., Abdul Latib, H., Subramaniam, H., and Khoo, A. (2018). "Innovation in the Malaysian furniture industry: Drivers and challenges," BioResources 13(3), 5254-5270. DOI: 10.15376/biores.13.3.5254-5270

Ratnasingam, J., Yi, L. Y., Abdul Azim, A., Halis, R., Choon Liat, L., Khoo, A., Mat Daud, M., Senin, A. L., Ab Latib, H., Bueno, M. V., et al. (2020). “Assessing the 
awareness and readiness of the Malaysian furniture industry for Industry 4.0," BioResources 15(3), 4866-4885. DOI: 10.15376/biores.15.3.4866-4885

Ratnasingam, J., Ramasamy, G., Ioras, F., Thanasegaran, G., and Muttiah, N. (2016). "Assessment of dust emission and working conditions in the bamboo and wooden furniture industries in Malaysia," BioResources 11(1), 1189-1201. DOI: 10.15376/biores.11.1.1189-1201

Russom, P. (2011). Big Data Analytics (TDWI Best Practices, Fourth Quarter Report), The Data Warehousing Institute, Renton, WA, USA.

Schröder, C. (2016). The Challenges of Industry 4.0 for Small and Medium-sized Enterprises, Friedrich-Ebert-Stiftung, Bonn, Germany.

Seseni, L., and Mbohwa, C. (2018). "Fourth industrial revolution and its impact on furniture manufacturing SMEs," in: Proceedings of the International Conference on Industrial Engineering and Operations Management, IEOM Society International, Washington D.C., USA, pp. 2572-2577.

Sommer, L. (2015). "Industrial revolution - Industry 4.0: Are German manufacturing SMEs the first victims of this revolution?" Journal of Industrial Engineering and Management 8(5), 1512-1532. DOI: 10.3926/jiem.1470

Stentoft, J., Wickstrøm, K. A., Philipsen, K., and Haug, A. (2020). "Drivers and barriers for Industry 4.0 readiness and practice: Empirical evidence from small and mediumsized manufacturers," Production Planning \& Control 32(10), 811-828. DOI: 10.1080/09537287.2020.1768318

Strandhagen, J. W., Alfnes, E., Strandhagen, J. O., and Vallandingham, L. R. (2017). "The fit of Industry 4.0 applications in manufacturing logistics: A multiple case study," Advances in Manufacturing 5(4), 344-358. DOI: 10.1007/s40436-017-0200-y

Tan, Z. Y. (2018). "Industry 4.0: The journey towards automation," The Edge Markets, (www.theedgemarkets.com/article/industry-40-journey-towards-automation), Accessed 15 Dec 2020.

Türkeș, M. C., Oncioiu, I., Aslam, H. D., Marin-Pantelescu, A., Topor, D. I., and Căpușneanu, S. (2019). "Drivers and barriers in using Industry 4.0: A perspective of SMEs in Romania," Processes 7(3), article no. 153. DOI: 10.3390/pr7030153

Wang, J., and Wu, Z. H. (2016). "The application of digital technologies in furniture design," in: Applied Engineering, Materials and Mechanics: Proceedings of the 2016 International Conference on Applied Engineering, Materials and Mechanics (ICAEMM 2016), Weihai, China, pp. 86-90.

$\mathrm{Xu}, \mathrm{X}$. (2012). "From cloud computing to cloud manufacturing," Robotics and Computer-Integrated Manufacturing 28(1), 75-86. DOI: 10.1016/j.rcim.2011.07.002

Yin, Y., Stecke, K. E., and Li, D. (2018). "The evolution of production systems from Industry 2.0 through Industry 4.0," International Journal of Production Research 56(1-2), 848-861. DOI: 10.1080/00207543.2017.1403664

Zanella, A., Bui, N., Castellani, A., Vangelista, L., and Zorzi, M. (2014). "Internet of things for smart cities," IEEE Internet of Things Journal 1(1), 22-32. DOI: 10.1109/JIOT.2014.2306328

Zawadzki, P., and Żywicki, K. (2016). "Smart product design and production control for effective mass customization in the Industry 4.0 concept," Management and Production Engineering Review 7(3), 105-112. DOI: 10.1515/mper-2016-0030 
Zhihui, W. (2016). "Manufacturing model of furniture industry in Industry 4.0," China Forest Products Industry 43(3), 7-12.

Article submitted: September 1, 2021; Peer review completed: October 17, 2021; Revised version received and accepted: October 24, 2021; Published: October 27, 2021.

DOI: $10.15376 /$ biores.16.4.8289-8308 